\title{
The belief-action gap in environmental psychology: How wide? How irrational?
}

\author{
Aurore Grandin ${ }^{1, a}$, Mélusine Boon-Falleur ${ }^{2}$ and Coralie Chevallier ${ }^{1}$ \\ 1. Laboratoire de neurosciences cognitives et computationnelles, Département d'études cognitives, \\ Ecole normale supérieure, Université PSL, INSERM, 75005 Paris, France. \\ 2. Institut Jean Nicod, Département d'études cognitives, Ecole normale supérieure, Université PSL, \\ EHESS, CNRS, 75005 Paris, France. \\ a. corresponding author: aurore.grandin@ens.psl.eu
}

\begin{abstract}
The belief-action gap was originally conceptualized by psychologists who aimed to ground behaviour in beliefs but found that their models had little predictive value. The recurrent use of this concept often comes with the assumption that human behaviour is somewhat irrational or weirdly misaligned with their beliefs. This gap is particularly striking in the environmental domain, where many people seemingly think one way but act another. In this chapter, we review a number of factors that hinder general beliefs from translating into actual behaviours. We emphasize the existence of measurement issues, information deficits about the exact impact of one's actions, structural factors and psychological factors that together impact the robustness of the association between beliefs and actions. In particular, socio-cognitive factors have a massive impact on people's decisions to act in ways that are aligned with their deepseated beliefs. Once all these factors are properly taken into account, it becomes clear that the belief-action gap is not a token of human irrationality but should in fact be expected.
\end{abstract}

\section{Keywords}

Belief-action gap; Knowledge-action gap; Value-action gap; Attitude-behaviour gap; Behavioural change; Pro-environmental behaviour; Social Cognition; Sustainability.

\section{Introduction}

The beliefs that climate change is real, that it is caused by human activities and that there is a scientific consensus about these issues are robust predictors of support for climate policy (Krosnick et al., 2006; McCright et al., 2013; van der Linden et al., 2015). Beyond mere policy support, climate-related beliefs are also associated with individual pro-environmental behaviours (Chen, 2015). Yet, despite the existence of this association, its strength is not as high as one might expect: when it comes to environmental issues, a gap is often observed between what people believe and what they actually do (Barr, 2004; Kennedy et al., 2009; Kollmuss \& Agyeman, 2002). In their meta-analytic review of 187 studies, Hines, Hungerford, 
and Tomera found that the relationship between pro-environmental attitudes and behaviour is moderate at best (Hines et al., 1987), and more recent meta-analyses have found even weaker associations, with correlations as low as 0.18 (Bamberg \& Möser, 2007) or even 0.09 (Klöckner, 2013) between environmental awareness and pro-environmental behaviour. Similarly, information campaigns on environmental issues are often effective at raising citizens' awareness but they have a disappointingly small impact on behaviour (Redondo \& Puelles, 2017). This phenomenon, known as "belief-action gap", "value-action gap", "knowledge-action gap", or "attitudes-behaviour inconsistency" has been a great puzzle for psychologists in the past decades. Why is the relationship between what people believe and what they actually do so weak? What can explain this discrepancy? Why don't people walk the talk when it comes to solving environmental problems?

This issue has become a major focus of psychological and educational research, both because of the theoretical questions it raises, and because of its practical relevance for policy makers who aim to preserve the environment. Beyond environmentalism, the question of the correspondence between beliefs and behaviour is relevant for many other societal issues. For instance, psychologists have long examined belief-action gaps in other domains such as birth control, health or racism (Conner et al., 2013; Davidson \& Jaccard, 1979; LaPiere, 1934). Faced with evidence that attitudes are not as strong predictors of behaviours as could be expected in many different domains, Allan W. Wicker concluded that attitudes were likely to be at best weakly correlated with behaviour (Wicker, 1969). This observation seemed to challenge the assumptions of coherence and rationality of human decisions, which are associated with the hypothesis that beliefs should be strong predictors of behaviour, a hypothesis which lies at the heart of influential models of human cognition such as the Theory of Reasoned Action and the Theory of Planned Behaviour (Ajzen, 1991; Fishbein \& Ajzen, 1977). This spurred a large amount of research to identify the multiple moderators of the beliefaction relationship (Armitage \& Christian, 2003). Collectively, many studies have now identified a catalogue of reasons behind the environmental belief-action gap (Blake, 1999; Gifford, 2011; Kollmuss \& Agyeman, 2002) and an entire issue of the Journal of Environmental Education Research was even dedicated to this topic twenty years ago (Courtenay-Hall \& Rogers, 2002; Kollmuss \& Agyeman, 2002; Maiteny, 2002). But after decades of research on the belief-action gap, we question whether this concept remains productive and argue that far from being symptoms of irrationality, gaps between what people think and what they do reveal the diversity of motivations behind people's behaviour.

\section{Measurement issues}

The very first, and perhaps underwhelming, reason why people's behaviour depart from their reported attitudes and beliefs is that our measurement tools may not be sophisticated enough to capture people's stable preferences and their specific instantiation in individual choices. In other words, one reason why people's actions differ from their beliefs is that measurement has an important moderating influence (Ajzen, 2005; Fishbein \& Ajzen, 1977). For instance, researchers measure overall environmental concern, and try to match it with specific pro-environmental behaviours, such as recycling or reduction in meat consumption. Yet, general attitudes are often poor predictors of specific behaviours (Ajzen, 2005), and a meta-analysis of eight studies found that specific attitudes are better predictors of specific behaviours than general attitudes (Kraus, 1995). This 'correspondence principle' 
might be particularly relevant in the case of pro-environmental behaviours, which are multidimensional and heterogenous (Blankenberg \& Alhusen, 2019; Stern, 2000). For instance, individuals' efforts to recycle may not necessarily translate in parallel efforts to ride a bicycle or take public transports instead of driving a car (Lynn, 2014). This has led some researchers to question whether general pro-environmental beliefs had any relevance at all to predict specific behaviour. In one study on green electricity, Bamberg found that a general measure of environmental concern had no significant direct effect on students' intention to ask for a brochure about green electricity products (or on their actual behaviour) when controlling for their attitudes towards green electricity: what mattered was these specific attitudes (Bamberg, 2003).

In addition, social desirability biases may affect the reliability of self-reported measures of attitudes and behaviours (Barr, 2006; Gifford \& Nilsson, 2014; Tarrant \& Cordell, 1997; but see Milfont (2009) for evidence that social desirability has no moderating effect on the attitudes-behaviour relationship). Temporal gaps in data collection may also impact the correlation, e.g., when data about people's attitudes and behaviour are not collected synchronously (Kollmuss \& Agyeman, 2002). A longitudinal study indeed showed that an increase in the time interval between the measurement of attitudes toward birth control pills and actual contraceptive use attenuated the strength of the relationship (Davidson \& Jaccard, 1979). A somewhat similar measurement problem applies to many studies on environmentalism, where pro-environmental behaviour is measured using a unique observation of a particular behaviour or a single choice in a questionnaire (e.g., donation to an environmental organisation), whereas environmental attitudes and beliefs are measured using multi-item scales spanning long periods of time (Milfont \& Duckitt, 2010). These scales are also designed to assess stable "traits", whereas measures of behaviour based on a single choice are more likely to be affected by random factors, such as unexpected external stimuli and contextual factors (Palminteri \& Chevallier, 2018).

To sum up, and as Andrew Gelman aptly notes, measurement is an overlooked but important matter: "When it comes to the question of how to take a sample or how to randomize, or the issues that arise (nonresponse, spillovers, selection, etc.) that interfere with the model, statistics textbooks take the practical issues seriously - even an intro statistics book will discuss topics such as blinding in experiments and self-selection in surveys. But when it comes to measurement, there's silence, just an implicit assumption that the measurement is what it is, that it's valid and that it's as reliable as it needs to be." (Gelman, 2015).

But let's imagine for a second that we had a perfect instrument to assess environmentalism, should we expect people to act according to their stated beliefs? Probably not. Beyond measurement inadequacy, many factors will push people to talk one way and live another.

\section{Information deficit and structural barriers}

One of these other factors is a potential information deficit. A basic knowledge of the risks associated with climate change, air pollution or ecosystem degradation is a prerequisite for the formation of pro-environmental attitudes. Environmental knowledge is also a necessary condition for people to be concerned and, in turn a necessary condition for people to adopt pro-environmental behaviour. Information deficit about the exact impact of one's actions and alternative behaviours that have lower impacts may indeed be a limiting factor that prevents people from taking action. 
Although there are substantial variations in levels of awareness across countries, many people across the world are aware of global warming (Gallup, 2008). Awareness that cars contribute to air pollution and that plastic waste pollutes is also high (Chin et al., 2019; Hammami et al., 2017). In many developed countries, the public is able to identify a number of behaviours that contribute to climate change and distinguish them from behaviours that are more eco-friendly. For instance, a recent study showed that North-American consumers were capable of appropriately ranking different types of food according to their level of greenhouse gas emissions (Camilleri et al., 2019).

But even when general awareness about environmental problems is high, people might lack precise and action-oriented knowledge, which might explain why we observe low engagement in environmental behaviours even among educated people who feel concerned about environmental degradation. Misconceptions about the contribution of daily behaviours to climate change and other environmental issues are indeed common. For example, most Europeans know that road traffic is a major source of air pollution, but underestimate the contribution of the agricultural sector to air pollution (Maione et al., 2020). The contribution of wood-stove heating to air pollution is also greatly underestimated by French citizens (Abdel Sater et al., 2020). Furthermore, Camilleri et al. (2019) demonstrated that although NorthAmerican consumers know that cattle farming emits more than apple production, they underestimate the magnitude of that difference. In addition, they are not able to estimate the exact quantity of $\mathrm{CO} 2$ that is necessary to produce most goods. Overall, participants in this study underestimated greenhouse gas emissions for foods and several appliances such as refrigerators and washing machines, while overestimating greenhouse gas emissions associated with laptop computers and DVD players (Camilleri et al., 2019). Similarly, when asked about the most effective strategies to reduce energy consumption, North-American respondents were able to name some actions, but the majority mentioned conservation behaviour such as turning off the lights, whereas experts unanimously recommend efficiency improvements in equipment (Attari et al., 2010). Respondents also tended to overestimate the consumption of low-energy activities and to underestimate the consumption of high-energy activities.

For people who are concerned about the environment, and who believe that it is important to take action, such misconceptions will have a downstream effect on the specific actions they decide to engage in. In line with this idea, the belief-action gap has been found to be smaller among people who have a better knowledge of climate change mechanisms (Babutsidze \& Chai, 2018).

However, even full awareness of environmental problems and knowledge about which behaviours are beneficial or detrimental to the environment does not systematically lead to action. For example, several studies report the testimony of British individuals who suggested that although they were aware of the consequences of air travel on climate change, they wanted to keep flying abroad for their holidays (Cohen \& Higham, 2011). Similarly, when presented with personalised and detailed information about their carbon footprint, most participants stated they were unwilling to reduce car or air travel, or change their diets (Büchs et al., 2018).

Beyond informational barriers, structural and situational factors play an important role. For instance, public transport might not be available or taking the bus might be more expensive than driving a car. Socioeconomic factors also act as a strong determinant of some proenvironmental behaviours, in particular those related to green consumption. For example, price is the most commonly cited barrier preventing people from buying organic food 
(Hansmann et al., 2020; Lea \& Worsley, 2005). Occupation also plays an important role, partly because it influences free time, which is positively associated with conservation behaviour (Chai et al., 2015). Similarly, families with children have a harder time performing proenvironmental behaviours (Longhi, 2013). This effect can be partially attributed to a reduced amount of free time and to the different activities associated with children's education. Lack of time was perceived by Canadian respondents as the main factor impeding pro-environmental action in the household (Kennedy et al., 2009). Other structural factors include lack of access to adequate infrastructure: for instance, lack of recycling facilities in the neighbourhood, or lack of public transports. In several European countries, individuals living in rural or suburban areas tend to have a higher direct carbon footprint than those living in cities, a pattern that can be mainly attributed to their greater use of cars due to limited access to public transport (Baiocchi et al., 2010; Tomás et al., 2020).

So where does the belief-action gap stand at this point? Once measurement issues, informational and structural issues are all accounted for, do people's actions still depart from their beliefs? The case of affluent and educated citizens is insightful in that respect: many people in high-income countries keep flying abroad for holidays and frequently eat meat, despite being well-aware of the negative impacts of these behaviours and having the means to make different choices (Büchs et al., 2018; Hurth, 2010).

\section{Psychological factors}

So why don't people who are well informed and have the means to do good don't always do it? People do not merely react to external forces but also to internal psychological factors, such as their sense of agency, their time preferences and socio-cognitive influences. For instance, research in psychology has shown that the sense of agency, a feeling of personal control over one's life outcomes, is a moderator of the relationship between beliefs about climate change and mitigation practices (Eom et al., 2018). Time preferences have also been identified as a moderator of the attitudes-behaviour relationship: future-oriented populations and individuals tend to display behaviours that are better aligned with their attitudes (Gu et al., 2020; Rabinovich et al., 2009; Tam \& Chan, 2017). In addition, perceived efforts associated with environmental behaviours plays an important role, such that environmental attitudes are good predictors of behaviours that are easy to perform, but not of difficult ones (Diekmann \& Preisendörfer, 2003; Farjam et al., 2019; Schultz \& Oskamp, 1996).

Besides, conflicting beliefs and attitudes can also prevent people from acting on their environmental concern. There are many attitudes relevant to any given behaviour, therefore the relationship between pro-environmental behaviour and pro-environmental attitudes may appear inconsistent simply because other attitudes that are more strongly held have not been considered (Wicker, 1969). For instance, some people might be aware of the detrimental impact of meat production on the environment, but might believe that they need to eat meat to stay healthy (see de Gavelle et al., 2019).

Aside from basic cognitive influences and conflicting beliefs, social cognition plays a massive role in moderating how people act based on the same belief. A single individual's impact on environmental protection is limited, which means that environmental problems are prototypical social dilemmas. Environmental issues are indeed public goods problems, where a group has to collectively manage a resource that benefits all its members, which implies that people can free-ride on others' efforts. For example, if everyone switches to a vegetarian diet, 
an individual can benefit from a global reduction in carbon emissions while privately continuing to consume meat. The nature of this social dilemma means that individuals will be willing to engage in pro-environmental behaviours only if they have sufficient evidence that other people are also doing so. In places where norms of cooperation are stronger and people have more trust in one another, the belief-action gap should therefore be smaller. In line with this idea, multi-level analyses have highlighted that social trust at the country level increases the strength of the association between environmental concern and pro-environmental behaviour (Tam \& Chan, 2018). Evidence shows that behavioural interventions aimed at making cooperative norms more salient have a large impact on pro-environmental behaviour. Such interventions have been successful to reduce energy consumption (Allcott, 2011), water consumption (Brent et al., 2017), travelling by car (Kormos et al., 2014), towel use in hotels (Goldstein et al., 2008), and to increase curbside recycling (Schultz, 1999).

These experimental results show that what people believe to be the social norm in their group is a strong determinant of their individual behaviour, often more so than their beliefs about the seriousness of environmental problems. Social norms that do not value proenvironmental behaviour may therefore act as barriers to the adoption of such behaviour. Research suggests that there can be a social stigma attached to being green in some segments of the population (Johnstone \& Tan, 2015), but that environmental protection has become a generally valued social norm in many countries (Bertoldo \& Castro, 2019). However, environmental protection is not valued to the same extent and in the same way in all social groups. For instance, studies show that it might not be as much a priority in poorer communities as it is in affluent ones (Kennedy \& Givens, 2019). In this perspective, adopting certain types of eco-responsible behaviours can be a way of demonstrating membership of a social group and signaling that one is a good cooperation partner.

Indeed, the cognitive mechanisms that regulate our reputation predict that individuals cooperate more when they are being monitored or can engage in signaling (Barclay \& Barker, 2020). Given that many pro-environmental behaviours such as avoiding long-distance plane travel or insulating one's home are not visible, individuals have no reputational incentives to engage in them. On the contrary, individuals will be more likely to engage in pro-environmental behaviours that are more visible, even paying a premium to make sure that their conservation efforts are conspicuous (Babutsidze \& Chai, 2018; Delgado et al., 2015). Research shows that when pro-environmental behaviours are visible, people engaging in such behaviours enjoy a better reputation and are favoured as cooperation partners (Barclay \& Barker, 2020; Griskevicius et al., 2010). However, if pro-environmental behaviours are chosen for their visibility and their ability to signal social status, this does not necessarily mean that they are the most effective for environmental protection, on the contrary. Driving a conspicuous hybrid car such as the Toyota Prius (see Delgado et al., 2015) might be more sustainable than driving a non-hybrid car, but it is far from being the most environmentally friendly transport option. Many conspicuous environmental behaviours are purely "tokenistic" green actions, meaning that they are visible and easy to achieve but do not have a very positive environmental impact. In addition, these tokenistic actions may coexist with other behaviours that are also intended to enhance good reputation, but which have a very negative impact on the environment. For example, in order to signal their wealth or their status, individuals may be incentivized to buy larger homes and bigger cars, in spite of their larger environmental footprint (Bellet, 2017; Hennighausen et al., 2016; Ramakrishnan et al., 2020).

This can explain why rich and educated people have a larger carbon footprint than less well-off people, despite a high level of environmental awareness and prevalent social norms about being an eco-responsible citizen (Hurth, 2010). We mentioned research showing that 
the belief-action gap of affluent people is lower than that of poor individuals (Eom et al., 2018), but it should be noted that this pattern is only observed when focusing on certain types of green behaviours that are easily accessible to the rich, but that do not necessarily have the greatest positive impact on the environment. This is different when we consider proenvironmental behaviours with high positive impact, such as avoiding or reducing flights for leisure and recreational purposes. A study found that although there was a positive association between individuals' environmental attitudes and their pro-environmental household behaviours, no correlation was found between their attitudes and their propensity to take nonwork related flights, or the distances flown by those who do so (Alcock et al., 2017). Many affluent people in developed countries indeed engage in green consumption while refusing to give up polluting behaviours such as flying abroad frequently, because they think it is too great a sacrifice (see Büchs et al., 2018). To reduce the cognitive dissonance induced by the coexistence of high environmental concern and highly polluting behaviours, they tend to fall back on tokenistic green actions, which have a low positive environmental impact but allow them to assuage the guilt, maintain a positive self-image and a good reputation. Compensatory beliefs, motivated inattention, motivated reasoning and delegation of responsibility help individuals reduce the dissonance caused by the persistence of environmentally detrimental behaviours (Hope et al., 2018).

Another social psychological factor that may affect people's willingness to act on their environmental concern is the importance placed on fairness and reciprocity. Evolutionary psychologists have demonstrated that fairness is central for cooperation to emerge and stabilize (Baumard, 2016). Individuals therefore need to balance their contribution. If they contribute too much to the interaction, they run the risk of being exploited by others. On the other hand, if they do not contribute enough, they will be left out for more generous partners (Debove et al., 2015). This social cognition mechanism can also impact the environmental belief-action gap. Although individuals may be willing to increase their effort to protect the environment, they might perceive existing solutions as unfair and therefore refuse to engage in them. This is particularly relevant for public policy support: studies show that people weigh fairness as much as they do individual benefits or efficiency concerns when assessing a public policy (Haferkamp et al., 2009; Huber et al., 2020). There is evidence that fairness concerns are critical to the acceptance of environmental public policies such as the carbon tax (Douenne \& Fabre, 2019; Sommer et al., 2020).

Together, these social psychological factors modulate the strength of the association between beliefs and actions. When pro-environmental behaviours are aligned with our social psychology, for example by being normative, visible and fair, we should expect the beliefaction gap to be smaller.

\section{Conclusion}

More than 20 years ago, researchers concluded that in spite of rising environmental awareness, few people take action to change their lifestyle in order to reach ambitious environmental goals (Blake, 1999). This assertion remains true today (see Büchs et al., 2018; Diekmann \& Preisendörfer, 2003), despite a concomitant surge in people's concern about environmental issues (Pew Research Center, 2019). In the presence of numerous constraints that weigh on them, individuals do not always behave as pro-environmentally as one would predict based only on their environmental attitudes and concerns. 
Of course, there are interactions between the three sets of obstacles that we highlight (information deficit, structural and psychological factors). Researchers often make a distinction between external and internal factors that explain the gap (Blake, 1999; Kollmuss \& Agyeman, 2002), but these different sets of variables can interact in many ways (Dietz et al., 1998). For instance, social structures impose external barriers that are impossible to overcome through personal behaviour, such as the lack of public transport when living in a remote rural area. Yet, the structures in which we live and that constrain our decisions also create internal obstacles such as habits that are difficult to change even when structures change, given that they consist in automating our behaviour (Aarts \& Dijksterhuis, 2000). When we are used to taking the car everyday, it is not easy to switch to public transport once a bus line is set up. Research on attitudes and habits suggests that attitudes may become irrelevant in guiding behaviour once a behaviour has become habitual (Triandis, 1979). Similarly, psychological factors and ideological preferences may also determine what information people seek, such that information deficits should not be considered as strictly exogenous: there is evidence of motivated ignorance in the environmental domain (Hertwig \& Engel, 2016; Shepherd \& Kay, 2012). In addition, psychological factors may influence the type of policies individuals support, which then creates structural barriers for environmental action.

The belief-action gap in the environmental domain limits our ability to effectively address environmental issues. Yet, after decades of research on the belief-action gap, should this discrepancy still come as a surprise? In light of measurement limitations and of all the informational, structural and psychological obstacles that we have reviewed -most of which have been known for a long time (see Blake, 1999; Wicker, 1969), what should come as a surprise is the idea that people's pro-environmental concerns would automatically translate in pro-environmental behaviour. In other words, a perfect belief-action alignment would be far more puzzling than a belief-action gap. Once we take into account people's knowledge and misperceptions about what works and what doesn't, people's beliefs about what they can realistically achieve given their economic, professional, geographical situation, and more importantly still, people's beliefs about what others are likely to do and about their individual duties under this social contract, there is no reason to be surprised that environmental concern is not the sole predictor of behaviour. People often do not act in a manner that is strictly aligned with their overall beliefs, however this is not a sign of irrationality. Instead, this is a rather unsurprising consequence of the fact that people's behaviour is the synthesis of multiple external and internal motives.

So why do researchers in social and behavioural science persist in referring to the belief-action gap? This phrase probably remains popular because the idea that knowledge, beliefs and attitudes are the main determinants of pro-environmental behaviour is intuitive. By contrast, many policy-makers and the general public remain unaware of the huge power of social motivation in steering behaviour. There is evidence that individuals tend to think that their environmental beliefs carry more weight in their decision making than the social influence of their peers, even though it is found to be untrue. A study showed that when asked about the main reasons for conserving energy, North-American respondents mostly referred to environmental concern and social responsibility, but the best predictor of their actual energy conservation was the behaviour of their neighbours in this domain (Nolan et al., 2008). These biased intuitions have important consequences because they steer policies towards tools to increase information about environmental issues, while overlooking the social factors that will prevent people from adopting pro-environmental behaviours, no matter how well informed they are. 
a.

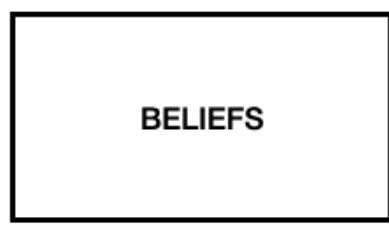

b.

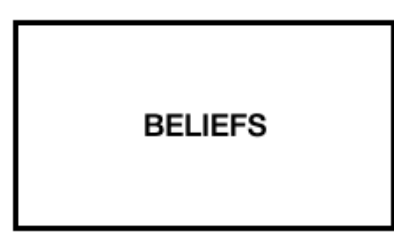

THE BELIEF-ACTION GAP

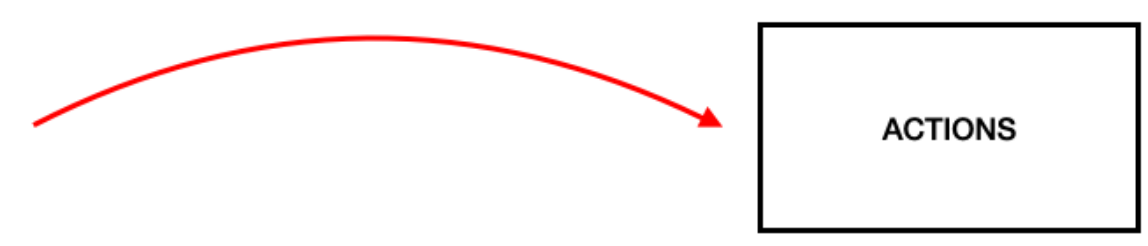

Figure 1. The belief-action in environmental psychology refers to the discrepancy between people's beliefs and attitudes regarding environmental degradation and their proenvironmental behaviour (figure a.). In this chapter, we argue that this gap results from a combination of (1) measurement issues, (2) information deficits and structural barriers, and (3) psychological factors (figure b.). Once these factors and their interactions are properly taken into account, the gap between beliefs and actions should no longer come as a surprise.

\section{Acknowledgements}

This work was supported by the EUR FrontCog grant ANR-17-EURE-0017.

\section{References}

Aarts, H., \& Dijksterhuis, A. (2000). Habits as knowledge structures : Automaticity in goaldirected behavior. Journal of Personality and Social Psychology, 78(1), 53-63. https://doi.org/10.1037/0022-3514.78.1.53

Abdel Sater, R., Perona, M., Huillery, E., \& Chevallier, C. (2020). Behavioural insights to reduce air pollution caused by wood burning. Evidence from a Randomized Controlled Trial in France. https://doi.org/10.17605/OSF.IO/5BR8Y 
Ajzen, I. (1991). The theory of planned behavior. Organizational behavior and human decision processes, 50(2), 179-211.

Ajzen, I. (2005). Laws of human behavior: Symmetry, compatibility, and attitude-behavior correspondence. Multivariate research strategies, 3-19.

Alcock, I., White, M. P., Taylor, T., Coldwell, D. F., Gribble, M. O., Evans, K. L., Corner, A., Vardoulakis, S., \& Fleming, L. E. (2017). 'Green' on the ground but not in the air : Pro-environmental attitudes are related to household behaviours but not discretionary air travel. Global Environmental Change, 42, 136-147. https://doi.org/10.1016/j.gloenvcha.2016.11.005

Allcott, H. (2011). Social norms and energy conservation. Journal of Public Economics, 95(9-10), 1082-1095. https://doi.org/10.1016/j.jpubeco.2011.03.003

Armitage, C. J., \& Christian, J. (2003). From attitudes to behaviour: Basic and applied research on the theory of planned behaviour. Current Psychology, 22(3), 187-195.

Attari, S. Z., DeKay, M. L., Davidson, C. I., \& Bruin, W. B. de. (2010). Public perceptions of energy consumption and savings. Proceedings of the National Academy of Sciences, 107(37), 16054-16059. https://doi.org/10.1073/pnas.1001509107

Babutsidze, Z., \& Chai, A. (2018). Look at me saving the planet! The imitation of visible green behavior and its impact on the climate value-action gap. Ecological Economics, 146, 290-303.

Baiocchi, G., Minx, J., \& Hubacek, K. (2010). The impact of social factors and consumer behavior on carbon dioxide emissions in the United Kingdom : A regression based on input- output and geodemographic consumer segmentation data. Journal of Industrial Ecology, 14(1), 50-72.

Bamberg, S. (2003). How does environmental concern influence specific environmentally related behaviors? A new answer to an old question. Journal of environmental psychology, 23(1), 21-32.

Bamberg, S., \& Möser, G. (2007). Twenty years after Hines, Hungerford, and Tomera: A 
new meta-analysis of psycho-social determinants of pro-environmental behaviour. Journal of Environmental Psychology, 27(1), 14-25.

https://doi.org/10.1016/j.jenvp.2006.12.002

Barclay, P., \& Barker, J. L. (2020). Greener Than Thou : People who protect the environment are more cooperative, compete to be environmental, and benefit from reputation. Journal of Environmental Psychology, 72, 101441.

https://doi.org/10.1016/j.jenvp.2020.101441

Barr, S. (2004). Are we all environmentalists now? Rhetoric and reality in environmental action. Geoforum, 35(2), 231-249.

Barr, S. (2006). Environmental action in the home: Investigating the « value-action » gap. Geography, 43-54.

Baumard, N. (2016). The Origins of Fairness : How Evolution Explains Our Moral Nature. Oxford University Press.

Bellet, C. (2017). The Paradox of the Joneses Superstar Houses and Mortgage Frenzy in Suburban America. CEP Discussion Paper No 1462.

Bertoldo, R., \& Castro, P. (2019). From legal to normative : A combined social representations and sociocognitive approach to diagnosing cultural change triggered by new environmental laws. Culture \& Psychology, 25(3), 324-344.

Blake, J. (1999). Overcoming the 'value-action gap' in environmental policy: Tensions between national policy and local experience. Local environment, 4(3), 257-278.

Blankenberg, A.-K., \& Alhusen, H. (2019). On the determinants of pro-environmental behavior: A literature review and guide for the empirical economist.

Brent, D. A., Lott, C., Taylor, M., Cook, J., Rollins, K., Stoddard, S., Brent, D. A., Lott, C., Taylor, M., \& Cook, J. (2017). Are normative appeals moral taxes? Evidence from a field experiment on water conservation. Louisiana State Department of Economics Working Papers Series.

Büchs, M., Bahaj, A. S., Blunden, L., Bourikas, L., Falkingham, J., James, P., Kamanda, M., 
\& Wu, Y. (2018). Promoting low carbon behaviours through personalised information? Long-term evaluation of a carbon calculator interview. Energy Policy, 120, 284-293.

Camilleri, A. R., Larrick, R. P., Hossain, S., \& Patino-Echeverri, D. (2019). Consumers underestimate the emissions associated with food but are aided by labels. Nature Climate Change, 9(1), 53-58. https://doi.org/10.1038/s41558-018-0354-z

Chai, A., Bradley, G., Lo, A., \& Reser, J. (2015). What time to adapt? The role of discretionary time in sustaining the climate change value-action gap. Ecological Economics, 116, 95-107.

Chen, M.-F. (2015). An examination of the value-belief-norm theory model in predicting proenvironmental behaviour in Taiwan. Asian Journal of Social Psychology, 18(2), 145-151. https://doi.org/10.1111/ajsp.12096

Chin, Y. S. J., Pretto, L. D., Thuppil, V., \& Ashfold, M. J. (2019). Public awareness and support for environmental protection-A focus on air pollution in peninsular Malaysia. PLOS ONE, 14(3), e0212206. https://doi.org/10.1371/journal.pone.0212206

Cohen, S. A., \& Higham, J. E. (2011). Eyes wide shut? UK consumer perceptions on aviation climate impacts and travel decisions to New Zealand. Current Issues in Tourism, 14(4), 323-335.

Conner, M., McEachan, R., Jackson, C., McMillan, B., Woolridge, M., \& Lawton, R. (2013). Moderating Effect of Socioeconomic Status on the Relationship between Health Cognitions and Behaviors. Annals of Behavioral Medicine, 46(1), 19-30. https://doi.org/10.1007/s12160-013-9481-y

Courtenay-Hall, P., \& Rogers, L. (2002). Gaps in mind: Problems in environmental knowledge-behaviour modelling research. Environmental Education Research, 8(3), 283-297.

Davidson, A. R., \& Jaccard, J. J. (1979). Variables that moderate the attitude-behavior relation : Results of a longitudinal survey. Journal of Personality and Social 
Psychology, 37(8), 1364.

Debove, S., André, J.-B., \& Baumard, N. (2015). Partner choice creates fairness in humans. Proceedings of the Royal Society B: Biological Sciences, 282(1808), 20150392. https://doi.org/10.1098/rspb.2015.0392

de Gavelle, E., Davidenko, O., Fouillet, H., Delarue, J., Darcel, N., Huneau, J.-F., \& Mariotti, F. (2019). Self-declared attitudes and beliefs regarding protein sources are a good prediction of the degree of transition to a low-meat diet in France. Appetite, 142, 104345.

Delgado, M. S., Harriger, J. L., \& Khanna, N. (2015). The value of environmental status signaling. Ecological Economics, 111, 1-11.

https://doi.org/10.1016/j.ecolecon.2014.12.021

Diekmann, A., \& Preisendörfer, P. (2003). Green and greenback: The behavioral effects of environmental attitudes in low-cost and high-cost situations. Rationality and Society, 15(4), 441-472.

Dietz, T., Stern, P. C., \& Guagnano, G. A. (1998). Social structural and social psychological bases of environmental concern. Environment and behavior, 30(4), 450-471.

Douenne, T., \& Fabre, A. (2019). Can we reconcile French people with the carbon tax? Disentangling beliefs from preferences.

Eom, K., Kim, H. S., \& Sherman, D. K. (2018). Social class, control, and action : Socioeconomic status differences in antecedents of support for pro-environmental action. Journal of Experimental Social Psychology, 77, 60-75. https://doi.org/10.1016/j.jesp.2018.03.009

Farjam, M., Nikolaychuk, O., \& Bravo, G. (2019). Experimental evidence of an environmental attitude-behavior gap in high-cost situations. Ecological Economics, 166, 106434.

Fishbein, M., \& Ajzen, I. (1977). Belief, attitude, intention, and behavior: An introduction to theory and research.

Gallup. (2008). Awareness, Opinions About Global Warming Vary Worldwide. https://news.gallup.com/poll/117772/Awareness-Opinions-Global-Warming-Vary- 
Worldwide.aspx

Gelman, A. (2015). What's the most important thing in statistics that's not in the textbooks? Statistical Modeling, Causal Inference, and Social Science.

https://statmodeling.stat.columbia.edu/2015/04/28/whats-important-thing-statisticsthats-not-textbooks/

Gifford, R., \& Nilsson, A. (2014). Personal and social factors that influence proenvironmental concern and behaviour : A review. International Journal of Psychology. https://doi.org/10.1002/ijop.12034

Goldstein, N. J., Cialdini, R. B., \& Griskevicius, V. (2008). A Room with a Viewpoint : Using Social Norms to Motivate Environmental Conservation in Hotels. Journal of Consumer Research, 35(3), 472-482. https://doi.org/10.1086/586910

Griskevicius, V., Tybur, J. M., \& Van den Bergh, B. (2010). Going green to be seen : Status, reputation, and conspicuous conservation. Journal of Personality and Social Psychology, 98(3), 392-404. https://doi.org/10.1037/a0017346

Gu, D., Jiang, J., Zhang, Y., Sun, Y., Jiang, W., \& Du, X. (2020). Concern for the future and saving the earth: When does ecological resource scarcity promote proenvironmental behavior? Journal of Environmental Psychology, 72, 101501. https://doi.org/10.1016/j.jenvp.2020.101501

Haferkamp, A., Fetchenhauer, D., Belschak, F., \& Enste, D. (2009). Efficiency versus fairness: The evaluation of labor market policies by economists and laypeople. Journal of Economic Psychology, 30(4), 527-539. https://doi.org/10.1016/j.joep.2009.03.010

Hammami, M. B. A., Mohammed, E. Q., Hashem, A. M., Al-Khafaji, M. A., Alqahtani, F., Alzaabi, S., \& Dash, N. (2017). Survey on awareness and attitudes of secondary school students regarding plastic pollution : Implications for environmental education and public health in Sharjah city, UAE. Environmental Science and Pollution Research, 24(25), 20626-20633.

Hansmann, R., Baur, I., \& Binder, C. R. (2020). Increasing organic food consumption: An 
integrating model of drivers and barriers. Journal of Cleaner Production, 275, 123058.

Hennighausen, C., Hudders, L., Lange, B. P., \& Fink, H. (2016). What If the Rival Drives a Porsche? : Luxury Car Spending as a Costly Signal in Male Intrasexual Competition. Evolutionary Psychology, 14(4), 147470491667821. https://doi.org/10.1177/1474704916678217

Hertwig, R., \& Engel, C. (2016). Homo ignorans : Deliberately choosing not to know. Perspectives on Psychological Science, 11(3), 359-372.

Hines, J. M., Hungerford, H. R., \& Tomera, A. N. (1987). Analysis and Synthesis of Research on Responsible Environmental Behavior : A Meta-Analysis. The Journal of Environmental Education, 18(2), 1-8.

https://doi.org/10.1080/00958964.1987.9943482

Hope, A. L., Jones, C. R., Webb, T. L., Watson, M. T., \& Kaklamanou, D. (2018). The role of compensatory beliefs in rationalizing environmentally detrimental behaviors. Environment and behavior, 50(4), 401-425.

Huber, R. A., Wicki, M. L., \& Bernauer, T. (2020). Public support for environmental policy depends on beliefs concerning effectiveness, intrusiveness, and fairness. Environmental Politics, 29(4), 649-673. https://doi.org/10.1080/09644016.2019.1629171

Hurth, V. (2010). Creating sustainable identities: The significance of the financially affluent self. Sustainable Development, 18(3), 123-134.

Johnstone, M.-L., \& Tan, L. P. (2015). Exploring the gap between consumers' green rhetoric and purchasing behaviour. Journal of Business Ethics, 132(2), 311-328.

Kennedy, E. H., Beckley, T. M., McFarlane, B. L., \& Nadeau, S. (2009). Why We Don't “Walk the Talk" : Understanding the Environmental Values/Behaviour Gap in Canada. Human Ecology Review, 16(2), 10.

Kennedy, E. H., \& Givens, J. E. (2019). Eco-habitus or Eco-powerlessness? Examining 
Environmental Concern across Social Class. Sociological Perspectives, 62(5), 646-667. https://doi.org/10.1177/0731121419836966

Klöckner, C. A. (2013). A comprehensive model of the psychology of environmental behaviour-A meta-analysis. Global Environmental Change, 23(5), 1028-1038. https://doi.org/10.1016/j.gloenvcha.2013.05.014

Kollmuss, A., \& Agyeman, J. (2002). Mind the Gap : Why do people act environmentally and what are the barriers to pro-environmental behavior? Environmental Education Research, 8(3), 239-260. https://doi.org/10.1080/13504620220145401

Kormos, C., Gifford, R., \& Brown, E. (2014). The Influence of Descriptive Social Norm Information on Sustainable Transportation Behavior : A Field Experiment. Environment and Behavior, 47(5), 479-501.

Kraus, S. J. (1995). Attitudes and the prediction of behavior: A meta-analysis of the empirical literature. Personality and Social Psychology Bulletin, 21(1), 58-75. https://doi.org/10.1177/0146167295211007

Krosnick, J. A., Holbrook, A. L., Lowe, L., \& Visser, P. S. (2006). The Origins and Consequences of democratic citizens' Policy Agendas : A Study of Popular Concern about Global Warming. Climatic Change, 77(1), 7-43. https://doi.org/10.1007/s10584006-9068-8

LaPiere, R. T. (1934). Attitudes vs. Actions. Social forces, 13(2), 230-237.

Lea, E., \& Worsley, T. (2005). Australians' organic food beliefs, demographics and values. British food journal.

Longhi, S. (2013). Individual pro-environmental behaviour in the household context. ISER Working Paper Series.

Lynn, P. (2014). Distinguishing dimensions of pro-environmental behaviour. ISER Working Paper Series.

Maione, M., Mocca, E., Eisfeld, K., Kazepov, Y., \& Fuzzi, S. (2020). Public perception of air pollution sources across Europe. Ambio, 1-9. 
Maiteny, P. T. (2002). Mind in the Gap : Summary of research exploring « inner » influences on pro-sustainability learning and behaviour.

McCright, A. M., Dunlap, R. E., \& Xiao, C. (2013). Perceived scientific agreement and support for government action on climate change in the USA. Climatic Change, 119(2), 511-518. https://doi.org/10.1007/s10584-013-0704-9

Milfont, T. L. (2009). The effects of social desirability on self-reported environmental attitudes and ecological behaviour. The Environmentalist, 29(3), 263-269.

Milfont, T. L., \& Duckitt, J. (2010). The environmental attitudes inventory : A valid and reliable measure to assess the structure of environmental attitudes. Journal of Environmental Psychology, 30(1), 80-94. https://doi.org/10.1016/j.jenvp.2009.09.001

Nolan, J. M., Schultz, P. W., Cialdini, R. B., Goldstein, N. J., \& Griskevicius, V. (2008). Normative social influence is underdetected. Personality and social psychology bulletin, 34(7), 913-923.

Palminteri, S., \& Chevallier, C. (2018). Can We Infer Inter-Individual Differences in RiskTaking From Behavioral Tasks? Frontiers in Psychology, 9. https://doi.org/10.3389/fpsyg.2018.02307

Pew Research Center. (2019). A look at how people around the world view climate change. Pew Research Center. https://www.pewresearch.org/fact-tank/2019/04/18/a-look-athow-people-around-the-world-view-climate-change/

Rabinovich, A., Morton, T., \& Postmes, T. (2009). Time perspective and attitude-behaviour consistency in future-oriented behaviours. The British Journal of Social Psychology, 49(Pt 1), 69-89.

Ramakrishnan, A., Kalkuhl, M., Ahmad, S., \& Creutzig, F. (2020). Keeping up with the Patels : Conspicuous consumption drives the adoption of cars and appliances in India. Energy Research \& Social Science, 70, 101742. https://doi.org/10.1016/j.erss.2020.101742

Redondo, I., \& Puelles, M. (2017). The connection between environmental attitude-behavior 
gap and other individual inconsistencies : A call for strengthening self-control. International Research in Geographical and Environmental Education, 26(2), 107-120. https://doi.org/10.1080/10382046.2016.1235361

Schultz, P. W. (1999). Changing Behavior With Normative Feedback Interventions : A Field Experiment on Curbside Recycling. Basic and Applied Social Psychology, 21(1), 25-36. https://doi.org/10.1207/s15324834basp2101_3

Schultz, P. W., \& Oskamp, S. (1996). Effort as a moderator of the attitude-behavior relationship : General environmental concern and recycling. Social psychology quarterly, 375-383.

Shepherd, S., \& Kay, A. C. (2012). On the perpetuation of ignorance : System dependence, system justification, and the motivated avoidance of sociopolitical information. Journal of Personality and Social Psychology, 102(2), 264-280. https://doi.org/10.1037/a0026272

Sommer, S., Mattauch, L., \& Pahle, M. (2020). Supporting carbon taxes: The role of fairness. Ruhr Economic Papers.

Stern, P. C. (2000). New environmental theories: Toward a coherent theory of environmentally significant behavior. Journal of social issues, 56(3), 407-424.

Tam, K.-P., \& Chan, H.-W. (2017). Environmental concern has a weaker association with pro-environmental behavior in some societies than others : A cross-cultural psychology perspective. Journal of Environmental Psychology, 53, 213-223.

Tam, K.-P., \& Chan, H.-W. (2018). Generalized trust narrows the gap between environmental concern and pro-environmental behavior: Multilevel evidence. Global Environmental Change, 48, 182-194. https://doi.org/10.1016/j.gloenvcha.2017.12.001

Tarrant, M. A., \& Cordell, H. K. (1997). The effect of respondent characteristics on general environmental attitude-behavior correspondence. Environment and behavior, 29(5), 618-637.

Tomás, M., López, L. A., \& Monsalve, F. (2020). Carbon footprint, municipality size and 
rurality in Spain : Inequality and carbon taxation. Journal of Cleaner Production, 266, 121798. https://doi.org/10.1016/j.jclepro.2020.121798

Triandis, H. C. (1979). Values, attitudes, and interpersonal behavior. Nebraska Symposium on Motivation, 27, 195-259.

van der Linden, S. L., Leiserowitz, A. A., Feinberg, G. D., \& Maibach, E. W. (2015). The scientific consensus on climate change as a gateway belief : Experimental evidence. PloS one, 10(2), e0118489.

Wicker, A. W. (1969). Attitudes versus actions: The relationship of verbal and overt behavioral responses to attitude objects. Journal of Social issues, 25(4), 41-78. 